University of Wollongong

Research Online

Australian Institute for Innovative Materials -

Papers

Australian Institute for Innovative Materials

$1-1-2016$

Ambient synthesis of one-/two-dimensional CuAgSe ternary nanotubes as counter electrodes of quantum-dot-sensitized solar cells

Xin Qi Chen

University of Wollongong

Yang Bai

University of Queensland

Zhen Li

University of Wollongong, zhenl@uow.edu.au

Lian Zhou Wang

University of Queensland

S X. Dou

University of Wollongong, shi@uow.edu.au

Follow this and additional works at: https://ro.uow.edu.au/aiimpapers

Part of the Engineering Commons, and the Physical Sciences and Mathematics Commons

Research Online is the open access institutional repository for the University of Wollongong. For further information contact the UOW Library: research-pubs@uow.edu.au 


\title{
Ambient synthesis of one-/two-dimensional CuAgSe ternary nanotubes as counter electrodes of quantum-dot-sensitized solar cells
}

\author{
Abstract \\ 2015 WILEY-VCH Verlag GmbH \& Co. KGaA, Weinheim. One-/two-dimensional ternary CuAgSe nanotubes \\ (NTs) were successfully prepared from copper selenide (Cu2-xSe) NTs at room temperature within a short \\ reaction time by the facile cation-exchange approach. Cation exchange leads to the transformation of the \\ crystal structure from cubic into orthorhombic and/or tetragonal with good retention of morphology. The \\ exchange reactions are spontaneous owing to large negative changes of the Gibbs free energy. The \\ effects of parameters such as reaction time, precursor source, and precursor ratio on the exchange \\ reaction were investigated. The resultant CuAgSe NTs were explored as counter electrodes (CEs) of \\ quantum-dot-sensitized solar cells (QDSSCs) and achieved higher conversion efficiency $(\eta=5.61 \%)$ than \\ those of QDSSCs with the gold as the CE (3.32\%).

\section{Keywords} \\ ambient, cells, solar, sensitized, dot, quantum, electrodes, counter, nanotubes, ternary, cuagse, \\ dimensional, two, one, synthesis

\section{Disciplines} \\ Engineering | Physical Sciences and Mathematics

\section{Publication Details} \\ Chen, X., Bai, Y., Li, Z., Wang, L. \& Dou, S. Xue. (2016). Ambient synthesis of one-/two-dimensional CuAgSe \\ ternary nanotubes as counter electrodes of quantum-dot-sensitized solar cells. ChemPlusChem, 81 (4), \\ 414-420.
}




\title{
Ambient Synthesis of One-/Two-Dimensional CuAgSe Ternary Nanotubes as Counter Electrodes of Quantum- Dot-Sensitized Solar Cells
}

\author{
Xin Qi Chen, ${ }^{[a, d]}$ Yang Bai, ${ }^{[c]}$ Zhen Li, $^{*[a, b]}$ Lian Zhou Wang, ${ }^{[c]}$ and Shi Xue Dou ${ }^{[a]}$
}

One-/two-dimensional ternary CuAgSe nanotubes (NTs) were
successfully prepared from copper selenide $\left(\mathrm{Cu}_{2-x} \mathrm{Se}\right) \mathrm{NTs}$ at
room temperature within a short reaction time by the facile
cation-exchange approach. Cation exchange leads to the trans-
formation of the crystal structure from cubic into orthorhom-
bic and/or tetragonal with good retention of morphology. The
exchange reactions are spontaneous owing to large negative changes of the Gibbs free energy. The effects of parameters such as reaction time, precursor source, and precursor ratio on the exchange reaction were investigated. The resultant CuAgSe NTs were explored as counter electrodes (CEs) of quantum-dot-sensitized solar cells (QDSSCs) and achieved higher conversion efficiency $(\eta=5.61 \%)$ than those of QDSSCs with the gold as the CE (3.32\%).

\section{Introduction}

One-/two-dimensional (1D/2D) ternary semiconductor nanotubes (NTs) have been the subject of extensive studies not only because their electronic structures and properties can be engineered over a broad range for diverse applications such as photodetectors, ${ }^{[1,2]}$ photovoltaics, ${ }^{[3]}$ and electronics, ${ }^{[4]}$ but also because their unique morphology consists of internal tubes and external nanosheets to form a large surface area, which enables them to be good electron transporters and show better performance than that of solid analogues. ${ }^{[5]}$ For example, ternary CuAgSe has high mobility from both $\mathrm{Cu}^{+}$and $\mathrm{Ag}^{+}$

[a] X. Q. Chen, Prof. Z. Li, Prof. S. X. Dou

Institute for Superconducting and Electronic Materials, Squires Way

Innovation Campus of the University of Wollongong

Wollongong, 2500, New South Wales (Australia)

Fax: (+61)2-42215731

E-mail:zhenl@uow.edu.au

zhenli@suda.edu.cn

[b] Prof. Z. Li

School of Radiation Medicine and Radiation Protection Collaborative Innovation Center of Radiation Medicine of Jiangsu Higher Education Institutions

Soochow University, 199 Ren Ai Road, Suzhou Industrial Park Suzhou 215123 (P.R. China)

[c] Dr. Y. Bai, Prof. L. Z. Wang

Nanomaterials Centre, School of Chemical Engineering and Australian Institute for Bioengineering and Nanotechnology (AIBN) University of Queensland, QLD 4072 (Australia)

[d] X. Q. Chen

Institute of Nanoscience and Nanotechnology

Department of Physics, Central China Normal University Wuhan, 430079 (P.R. China)

$\square$ Supporting information for this article is available on the WWW under http://dx.doi.org/10.1002/cplu.201500466. It contains low-magnification the SEM image and EDX pattern of CuAgSe NTs, XRD patterns of CuSe and $\mathrm{Ag}_{2} \mathrm{Se}, \mathrm{XRD}$ patterns of the products prepared from different molar ratios of $\mathrm{Cu}_{2-x}$ Se to $\mathrm{AgNO}_{3}, \mathrm{XRD}$ patterns and SEM images of CuAgSe NTs, and XPS spectra of Ag $3 \mathrm{~d}$ in the samples prepared from silver acetate and collected after different reaction times. ions, and displays better performance than binary $\mathrm{Ag}_{2} \mathrm{Se}$ or $\mathrm{Cu}_{2} \mathrm{Se}$ in electrochemical devices. ${ }^{[6-8]}$ This material was initially reported in the $1950 \mathrm{~s},{ }^{[9,10]}$ and has been rarely studied owing to difficulties in synthesis, especially for the preparation of nanostructures. Ternary CuAgSe is conventionally synthesized by heating a mixture of $\mathrm{Ag}, \mathrm{Cu}$, and Se powder to over $1000 \mathrm{~K}$ with several heating and cooling steps. ${ }^{[11,12]}$ Thin CuAgSe films can be prepared by the electrodeposition method. ${ }^{[13]}$ The crystal size of the products generated by these methods is quite large and uncontrollable, and recent advances in nanofabrication have led to new insights into the preparation and application of ternary CuAgSe nanostructures. For example, surfactant-free CuAgSe nanoparticles were prepared on a large scale to show the temperature-dependent reversible transition of metallic $n-p$ conductivity, and great potential in converting heat into electricity through the Seebeck effect. ${ }^{[14]}$ Both dendritic and tubular CuAgSe were prepared from $\mathrm{Ag}_{2} \mathrm{Se} / \mathrm{Ag}$ or $\mathrm{Ag}_{2} \mathrm{Se} / \mathrm{Se}$ templates, ${ }^{[6,15]}$ but it was time consuming and difficult to avoid $\mathrm{Ag}$ or Se in the final products. Thus, a facile and efficient method for the synthesis of ternary CuAgSe nanomaterials with well-defined composition and architecture is desirable.

Compared with the aforementioned approaches, cation exchange has emerged as a particularly powerful and promising method to prepare well-defined nanoarchitectures. ${ }^{[16-20]}$ It offers a new avenue to create chemically and compositionally diverse nanomaterials, and is particularly suitable for the preparation of late-transition-metal chalcogenide nanostructures. ${ }^{[21-23]}$ This strategy has been successfully applied to prepare heterostructured, doped, alloyed, hollow, and core-shell nanocrystals; nanorods; and nanowires. ${ }^{[17,24-29]}$ For example, a dual-interface heterostructured copper sulfide layer capped with zinc sulfide grains in spherical nanocrystals were synthesized, and the extent of cation exchange could be precisely manipulated to tune the thickness of the internal layer down 
to the single-atom level. ${ }^{[17]}$ Hollow and cave-shaped nanoparticles of $\mathrm{Cu}_{2-x} \mathrm{~S}_{y} \mathrm{Se}_{1-y}$ were prepared from core-shell $\mathrm{Cu}_{2-x} \mathrm{Se} /$ $\mathrm{Cu}_{2-x} \mathrm{~S}$ nanocrystals by the diffusion of $\mathrm{Cu}^{+}$from the $\mathrm{Cu}_{2-x} \mathrm{Se}$ core into the $\mathrm{Cu}_{2-x} \mathrm{~S}$ shell. ${ }^{[29]}$ Recently, phase-selective cation exchange enabled the successful transition of $\mathrm{CdS}$ nanowires into $\mathrm{Cu}_{2-x} \mathrm{~S}$ nanowires with tunable crystal structures. ${ }^{[28]}$ Owing to complications of partial or complete cation exchange between binary compounds, very few reports are available on the preparation of hierarchical 1D/2D ternary CuAgSe NTs.

In this study, we synthesized 1D/2D ternary CuAgSe NTs from $\mathrm{Cu}_{2-x} \mathrm{Se}$ NTs through the facile cation-exchange method at room temperature with a short reaction time. The resultant CuAgSe NTs were employed as the counter electrodes (CEs) of quantum-dot-sensitized solar cells (QDSSCs) to generate a conversion efficiency $(\eta)$ of $5.61 \%$. To the best of our knowledge, this is the first report on $1 \mathrm{D} / 2 \mathrm{D}$ ternary CuAgSe NTs and their application in QDSSCs.

\section{Results and Discussion}

The 1D/2D ternary CuAgSe NTs were fabricated by cation exchange from freshly prepared $\mathrm{Cu}_{2-x} \mathrm{Se}$ NTs reacted with a solution of $\mathrm{AgNO}_{3}$ in ethanol. Typical field-emission (FE) SEM and TEM images of the initial $\mathrm{Cu}_{2-x}$ Se NTs show their 1D/2D morphology with an inner diameter of $300 \mathrm{~nm}$ and an outer diameter of $600 \mathrm{~nm}$, on average (Figure $1 \mathrm{a}, \mathrm{b}$ ). After partial exchange of copper ions with silver ions, the nanosheets on the surfaces of the resultant CuAgSe NTs become smaller (Figure $1 \mathrm{~d}$, e) and the 1D/2D tubular structure is retained (Figure S1 in the Supporting Information). The HRTEM images clearly display continuous lattice fringes with spacings of 0.33 and $0.2 \mathrm{~nm}$ (Figure 1c, f), which match well with those of the (111) planes of $\mathrm{Cu}_{2-x} \mathrm{Se}$ and the (152) planes of CuAgSe, respectively. The FFT patterns also support the transition of the crys-

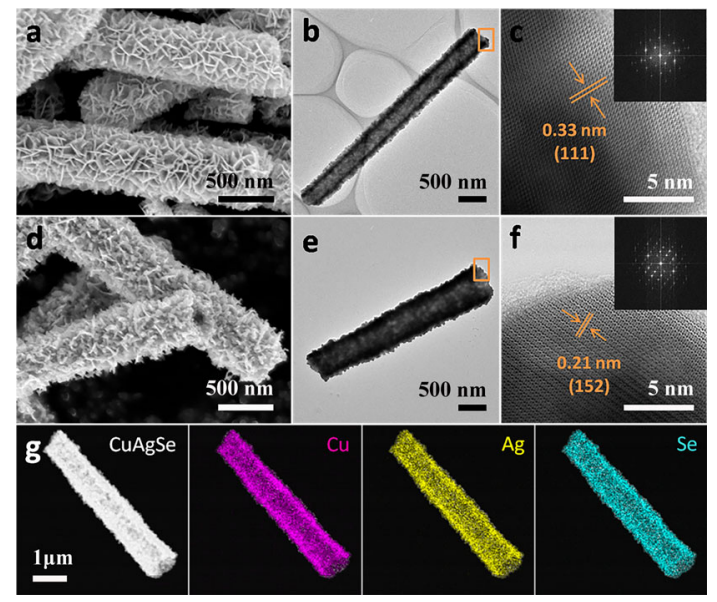

Figure 1. FESEM images of the $\mathrm{Cu}_{2-x} \mathrm{Se}$ NTs (a) and resultant CuAgSe NTs (d). TEM images of $\mathrm{Cu}_{2-x} \mathrm{Se}$ NT (b) and CuAgSe NT (e). c, f) High-resolution (HR) TEM images of the selected areas in (b) and (e), respectively. The insets contain fast Fourier transform (FFT) patterns of the HRTEM images. g) Scanning transmission electron microscopy (STEM) image and energy-dispersive X-ray spectroscopy (EDX) elemental mapping of $\mathrm{Cu}, \mathrm{Ag}$, and Se for a typical CuAgSe NT. tal structure after cation exchange. A STEM image and the corresponding EDX elemental mapping images of a single CuAgSe NT are shown in Figure $1 \mathrm{~g}$; these results reveal the homogeneous distribution of $\mathrm{Cu}, \mathrm{Ag}$, and $\mathrm{Se}$ throughout the whole NT. The EDX spectrum of an individual CuAgSe NT (Figure S2 in the Supporting Information) further confirms the presence of these elements with a ratio of $1.46 / 1.1 / 1$, which is consistent with that $(1.22 / 1 / 1.04)$ determined by inductively coupled plasma atomic emission spectroscopy (ICP-AES).

The transformation of $\mathrm{Cu}_{2-x}$ Se NTs into CuAgSe NTs is also proved by the XRD patterns (Figure 2). The diffraction peaks in the orange pattern in Figure 2 match well with orthorhombic CuAgSe (JCPDS 10-0451) and tetragonal CuAgSe (JCPDS 25$1180)$, which are different from those of the cubic structure of $\mathrm{Cu}_{2-x} \mathrm{Se}$ (JCPDS 88-2043; Figure 3). It should be noted that there is no big difference between these two structures, except that the orthorhombic structure features a sequence that repeats itself periodically every five tetragonal cells in the $b$ direction. ${ }^{[14]}$ They have similar layered structures with alternating stacking of the $\mathrm{Ag}$ and CuSe layers, in which $\mathrm{Ag}$ atoms almost lie in the same plane and are bonded closely to Se atoms, which allows high mobility of Ag atoms and the formation of $\mathrm{Ag}-\mathrm{Ag}$ metallic bonds. Selenium atoms form a squashed tetrahedron, in which each corner is shared with an adjacent tetrahedron, and copper atoms are offset from the center within the tetrahedron. ${ }^{[10]}$

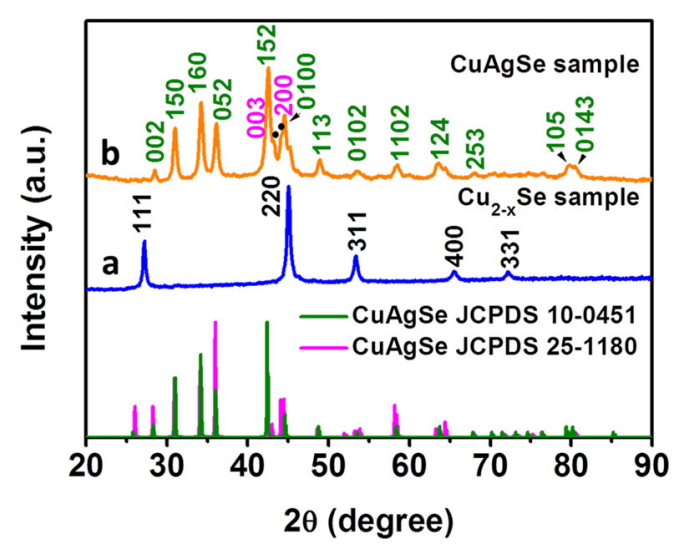

Figure 2. XRD patterns of a) $\mathrm{Cu}_{2-x} \mathrm{Se}$ NTs and b) CuAgSe NTs with standard XRD peaks.

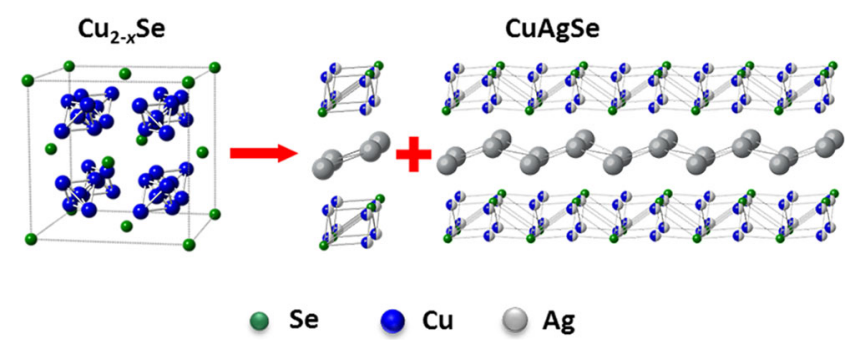

Figure 3. Structure diagrams of cubic $\mathrm{Cu}_{2-x} \mathrm{Se}$, and tetragonal and orthorhombic CuAgSe unit cells. 
Because stoichiometric $\mathrm{Cu}_{2} \mathrm{Se}$ is easily oxidized into nonstoichiometric $\mathrm{Cu}_{2-x} \mathrm{Se}^{[30]} \mathrm{X}$-ray photoelectron spectroscopy (XPS) was used to determine the valence states of elements in both $\mathrm{Cu}_{2-x} \mathrm{Se}$ and CuAgSe NTs (Figure 4). The spectra of $\mathrm{Cu} 2 \mathrm{p}$ confirm the presence of both $\mathrm{Cu}^{+}$and $\mathrm{Cu}^{2+}$ (with a calculated ratio of 3.16) in $\mathrm{Cu}_{2-x} \mathrm{Se} N T s$, from which the $\mathrm{Cu}^{2+}$ ions were completely transformed into $\mathrm{Cu}^{+}$in CuAgSe NTs after cation exchange, as evidenced by the disappearance of the characteristic peak of $\mathrm{Cu}^{2+}$ at around $942 \mathrm{eV}$. Two peaks at 373.2 and $367.6 \mathrm{eV}$ of $\mathrm{Ag} 3 \mathrm{~d}$ in the product indicate the absence of other Ag species. The binding energy of $\mathrm{Se} 3 \mathrm{~d}_{3 / 2}$ at $53.7 \mathrm{eV}$ corresponds to $\mathrm{Se}^{2-}$ in both $\mathrm{Cu}_{2-x} \mathrm{Se}$ and CuAgSe NTs, and the small peak at $58.2 \mathrm{eV}$ in the $\mathrm{Cu}_{2-x} \mathrm{Se}$ sample is attributed to surfaceadsorbed $\mathrm{Se}$ (the ratio of $\mathrm{Se}^{2-}$ to $\mathrm{Se}^{0}$ in $\mathrm{Cu}_{2-x} \mathrm{Se}$ was calculated to be 3.33). ${ }^{[14,31-33]}$

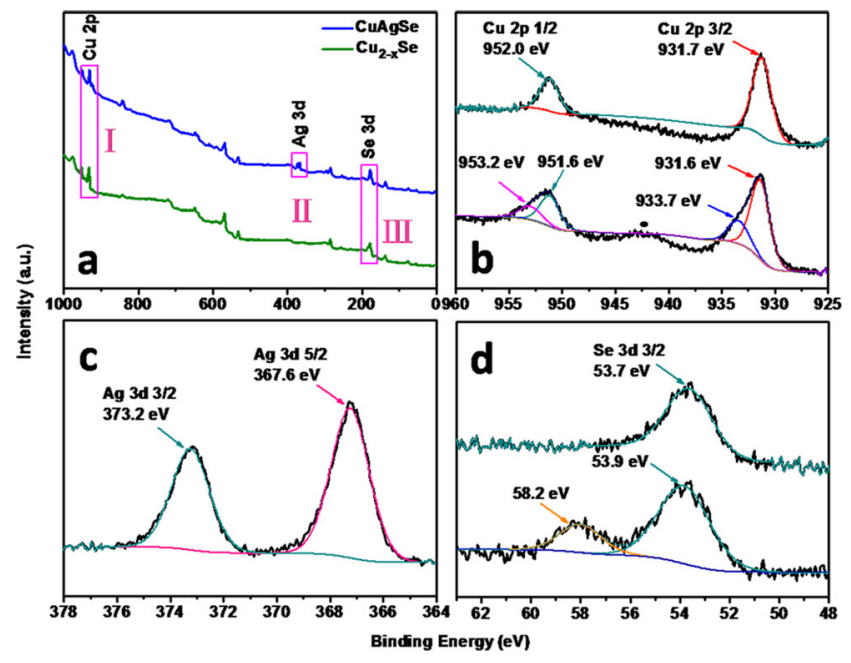

Figure 4. XPS spectra of $\mathrm{Cu}_{2-x}$ Se and CuAgSe NTs: a) survey spectra; b) $\mathrm{Cu}$ $2 \mathrm{p}$ spectra of area I in (a), with the black dot marking the satellite peak of $\mathrm{Cu}^{2+}$; c) $\mathrm{Ag} 3 \mathrm{~d}$ spectrum of area II in (a); and d) Se $3 \mathrm{~d}$ spectra of area III in (a).

The exchange reaction was investigated by analyzing the intermediate products collected after different reaction times. Figure 5 a shows the XRD patterns of samples collected at 1, 2, 10 , and 20 min during the exchange reaction. When a solution of $\mathrm{Cu}_{2-x} \mathrm{Se}$ in ethanol was reacted with a solution of $\mathrm{AgNO}_{3}$ in ethanol for $1 \mathrm{~min}$, the product obtained was a mixture of CuAgSe, $\mathrm{Ag}_{2} \mathrm{Se}$, and a small amount of $\mathrm{Ag}$. This result demonstrates the fast exchange reaction between copper and silver ions, which is attributed to their strong mobility and capability for diffusion into/out of the lattice. ${ }^{[7]}$ After reaction for 2 min, the product was still composed of these three compounds, but the amount of $\mathrm{Ag}_{2} \mathrm{Se}$ and $\mathrm{Ag}$ decreased, as indicated by the lower intensity of the peaks in the XRD patterns. The intermediate sample collected at $10 \mathrm{~min}$ was a mixture of CuAgSe and $\mathrm{Ag}_{2} \mathrm{Se}$, and the peak corresponding to Ag disappeared or was not detectable. The final product collected at $20 \mathrm{~min}$ was pure CuAgSe, which demonstrated the complete transformation of $\mathrm{Cu}_{2-x}$ Se NTs into CuAgSe NTs. The transformation was also supported by XPS spectra of $\mathrm{Ag}^{+}$and $\mathrm{Ag}^{0}$ in all samples
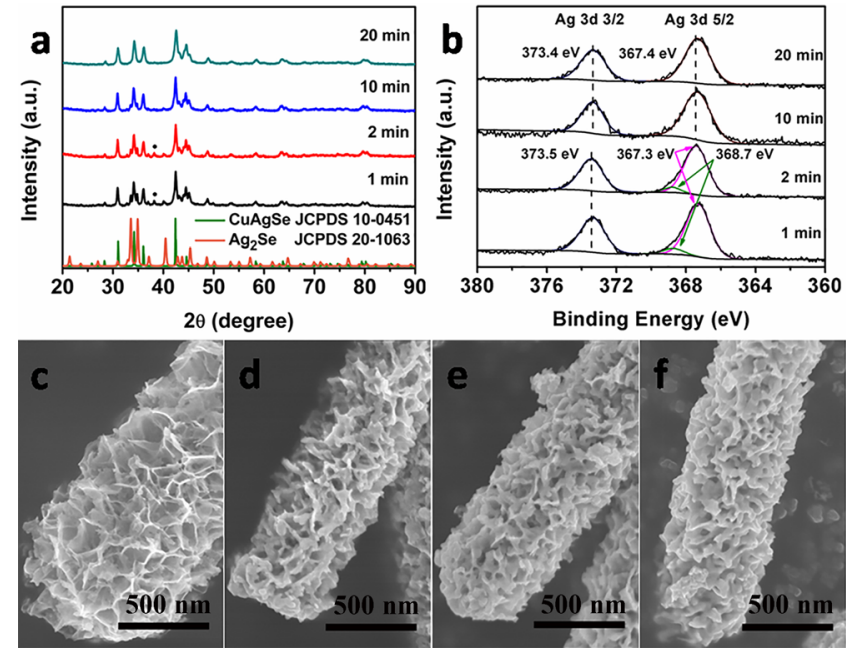

Figure 5. a) XRD patterns of products and b) XPS spectra of Ag $3 \mathrm{~d}$ from samples collected at different reaction times. The diffraction peaks marked with black dots arise from Ag. SEM images of NTs collected at c) 1, d) 2, e) 10 , and f) $20 \mathrm{~min}$.

collected at different reaction times (Figure $5 \mathrm{~b}$ ). Within the initial $2 \mathrm{~min}, \mathrm{Ag} 3 \mathrm{~d}_{5 / 2}$ peaks in the collected samples can be fitted into two peaks at $368.7\left(\mathrm{Ag}^{\circ}\right)$ and $367.3 \mathrm{eV}\left(\mathrm{Ag}^{+}\right)$. The $\mathrm{Ag}^{0} / \mathrm{Ag}^{+}$ratios in the samples collected at 1 and 2 min decreased from 12.83 to 10.48 , which meant that there was conversion of $\mathrm{Ag}^{0}$ into $\mathrm{Ag}^{+}$as the reaction time was extended. When the mixture was reacted for $10 \mathrm{~min}$, the absence of any $\mathrm{Ag}^{0}$ peak suggested that all $\mathrm{Ag}$ formed was completely converted. The evolution of the morphology during cation exchange was monitored by SEM (Figure $5 c-f$ ). There is no big difference in the morphologies, except that the surface nanosheets became thicker and rougher with increasing reaction time.

From the perspective of the molecular formula, $\mathrm{Cu}_{2-x} \mathrm{Se}$ $(0 \leq x \leq 1)$ could be considered as a mixture of CuSe and $\mathrm{Cu}_{2} \mathrm{Se}$, and the transformation of $\mathrm{Cu}_{2-x} \mathrm{Se}$ into CuAgSe could be treated as their reactions with $\mathrm{AgNO}_{3}$ [Eqs. (1) and (2)]. $\mathrm{Cu}_{2} \mathrm{Se}$ could react with $\mathrm{AgNO}_{3}$ to form CuAgSe, $\mathrm{Ag}$, and $\mathrm{Cu}\left(\mathrm{NO}_{3}\right)_{2}$ through the redox reactions between $\mathrm{Cu}^{+}, \mathrm{Ag}^{+}$, and $\mathrm{NO}_{3}{ }^{-}$, as evidenced by the XRD and XPS results. CuSe reacted with $\mathrm{AgNO}_{3}$ to form $\mathrm{Ag}_{2} \mathrm{Se}$ owing to its greater solubility ( $K_{\mathrm{sp}}$ $\left.(\mathrm{CuSe})=7.94 \times 10^{-49}\right)$ than that of $\mathrm{Ag}_{2} \mathrm{Se}\left(K_{\mathrm{sp}}\left(\mathrm{Ag}_{2} \mathrm{Se}\right)=2.0 \times\right.$ $\left.10^{-64}\right)$, which was proved by mixing a solution of pure CuSe in ethanol with a solution of $\mathrm{AgNO}_{3}$ in ethanol at room temperature to form $\mathrm{Ag}_{2} \mathrm{Se}$ (Figure $\mathrm{S} 3$ in the Supporting Information). The characteristic blue solution suggests the formation of $\mathrm{Cu}\left(\mathrm{NO}_{3}\right)_{2}$ during exchange reactions. Thus-formed $\mathrm{Ag}$ reacted with residual Se (adsorbed by $\mathrm{Cu}_{2-x} \mathrm{Se} N T s$ ) to form $\mathrm{Ag}_{2} \mathrm{Se}$ [Eq. (3)], which further reacted with $\mathrm{Cu}_{2} \mathrm{Se}$ to form CuAgSe [Eq. (4)]. ${ }^{[14]}$ To demonstrate these reactions, the effects of the molar ratio of $\mathrm{Cu}_{2-x} \mathrm{Se} N \mathrm{NT}$ to $\mathrm{AgNO}_{3}$ in the product were investigated. In the cases of more $\mathrm{Cu}_{2-x} \mathrm{Se}$ NTs (i.e., $\mathrm{Cu}_{2-x} \mathrm{Se}$ / $\mathrm{AgNO}_{3}=2.5 / 1$ or $1.5 / 1$ ), there is insufficient $\mathrm{AgNO}_{3}$ for the reactions and the main product is $\mathrm{Cu}_{2-x} \mathrm{Se}$, which is labeled with * in Figure S4 in the Supporting Information. In the opposite 
cases (i.e., $\mathrm{Cu}_{2-x} \mathrm{Se} / \mathrm{AgNO}_{3}=1 / 2$ or $1 / 3$ ), excess $\mathrm{AgNO}_{3}$ leads to the formation of $\mathrm{Ag}$ (marked with $\triangle$ in Figure S4 in the Supporting Information). Therefore, it is crucial to control the molar ratio of $\mathrm{Cu}_{2-x} \mathrm{Se} / \mathrm{AgNO}_{3}$; the optimal ratio is $1 / 1$.

$$
\begin{aligned}
& \mathrm{Cu}_{2} \mathrm{Se}+2 \mathrm{AgNO}_{3} \rightarrow \mathrm{CuAgSe}+\mathrm{Ag}+\mathrm{Cu}\left(\mathrm{NO}_{3}\right)_{2} \\
& \mathrm{CuSe}+2 \mathrm{AgNO}_{3} \rightarrow \mathrm{Ag}_{2} \mathrm{Se}+\mathrm{Cu}\left(\mathrm{NO}_{3}\right)_{2} \\
& 2 \mathrm{Ag}+\mathrm{Se} \rightarrow \mathrm{Ag}_{2} \mathrm{Se} \\
& \mathrm{Cu}_{2} \mathrm{Se}+\mathrm{Ag}_{2} \mathrm{Se} \rightarrow 2 \mathrm{CuAgSe}
\end{aligned}
$$

These exchange reactions took place spontaneously as a result of three factors. First, the high mobility of $\mathrm{Cu}^{2+}, \mathrm{Cu}^{+}$, and $\mathrm{Ag}^{+}$ions and their strong capability for diffusion into/out of the lattice ensure fast reactions. The presence of copper vacancies also significantly accelerates the cation-exchange process at room temperature. ${ }^{[34]}$ Second, the changes of Gibbs free energy $(\Delta G)$ for the reactions in Equations (1)-(4) are calculated to be $-85.7,-55.8,-43.5$, and $-84.4 \mathrm{~kJ} \mathrm{~mol}^{-1}$ based on the assumption that the reaction temperature is constant at $298 \mathrm{~K}$ and no entropy changes occur during the reaction. The standard $\Delta_{\mathrm{f}} \mathrm{H}^{0}$ values at $298 \mathrm{~K}$ for $\mathrm{Cu}_{2} \mathrm{Se}$, CuSe, $\mathrm{Ag}_{2} \mathrm{Se}$, $\mathrm{AgNO}_{3}, \mathrm{Cu}\left(\mathrm{NO}_{3}\right)_{2}$, and CuAgSe are -65.3, -41.8, -43.5, $-124.4,-302.9$, and $-96.9 \mathrm{~kJ} \mathrm{~mol}^{-1}$, respectively. ${ }^{[6,7,35,36]}$ Third, similar crystal structures of intermediate $\mathrm{Ag}_{2} \mathrm{Se}$ and the CuAgSe product minimize the distortion of the crystal structure.

To better control the exchange process, we selected silver acetate to repeat the experiments and collected the intermediate products after different exchange times (i.e., 1, 2, 10, 20, and $60 \mathrm{~min}$; Figures S5 and S6 in the Supporting Information). The results show that the complete transformation of $\mathrm{Cu}_{2-x} \mathrm{Se}$ NTs into CuAgSe NTs took $60 \mathrm{~min}$, owing to the lower dissociation capability of silver acetate in ethanol relative to that of $\mathrm{AgNO}_{3}$. The same intermediate products $\left(\mathrm{Ag}_{2} \mathrm{Se}\right.$ and $\left.\mathrm{Ag}\right)$ formed at an early stage (i.e., 1 and $2 \mathrm{~min}$ ) and confirmed the same exchange process discussed above. Similar to the product prepared from $\mathrm{AgNO}_{3}$, the morphology of CuAgSe NTs obtained from silver acetate is retained (Figure S7 in the Supporting Information).

As mentioned above, ternary CuAgSe might exhibit better electrochemical performance than that of its binary counterparts. ${ }^{[37]}$ To evaluate the electrocatalytic activity, the resulting 1D/2D CuAgSe NTs were fabricated into CEs and then assembled with $\mathrm{CdS} / \mathrm{CdSe}$ quantum dot (QD)-sensitized photoanodes to construct QDSSC devices containing polysulfide electrolyte. The electrocatalytic activities were compared with those of CEs fabricated from $\mathrm{Cu}_{2-x} \mathrm{Se}$ NTs and Au under the same conditions. ${ }^{[38,39]}$ The average photovoltaic performance parameters are provided in Table 1. Compared with the $\mathrm{Cu}_{2-x} \mathrm{Se} N \mathrm{NT}$ and $\mathrm{Au}$ CEs, QDSSCs incorporating CuAgSe NT CEs delivered a larger $J_{\mathrm{sc}}$ value of $17.57 \mathrm{~mA} \mathrm{~cm}^{-2}$ (Figure $6 \mathrm{a}$ ), which indicated the fast reduction of $S_{n}{ }^{2-}$ to $n S^{2-}$. In addition, the remarkable enhancement of the $V_{\text {oc }}$ value of $581 \mathrm{mV}$, FF of $55.0 \%$, can be ascribed to better electrical conductivity, and thus, suppressed charge
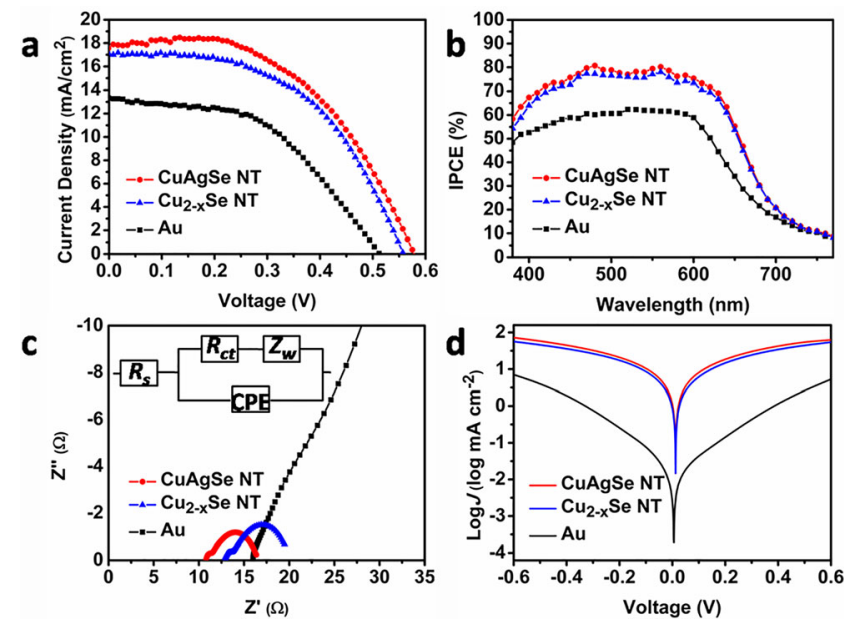

Figure 6. a) The photocurrent density-voltage $(J-V$ curves and $b)$ incident photon-to-electron conversion efficiency (IPCE) spectra of QDSSCs with different CEs. c) Nyquist plots of the symmetrical dummy cells fabricated with three CEs; the inset shows the equivalent circuit. d) Tafel polarization of different dummy cells that were the same as those used for electrochemical impedance spectroscopy (EIS) measurements.

recombination. Figure $6 \mathrm{~b}$ shows the IPCE spectra of typical QDSSCs based on three different CEs. Compared with both Au and $\mathrm{Cu}_{2-x}$ Se NT CEs, the IPCE profile of QDSSCs employing the CuAgSe NT CE is higher over the entire wavelength region. This is consistent with the achieved $J_{s c}$ value. The significant increase in IPCE further verified that CuAgSe NTs possessed both super catalytic activity and high electrical conductivity. To understand the improved QDSSC performance, EIS and Tafel polarization measurements were performed on dummy cells assembled with two identical electrodes. Figure $6 \mathrm{c}$ shows the Nyquist plots of the dummy cells with different CEs. The inset equivalent circuit includes $R_{\mathrm{s}}, R_{\mathrm{ct}}$ and $Z_{\mathrm{w}}$. A smaller resistance means better electrocatalytic activity of the CEs. ${ }^{[40-42]}$ The $R_{\mathrm{s}}$ value of the CuAgSe CE (10.8 $\Omega$ ) is smaller than those of the $\mathrm{Cu}_{2-x} \mathrm{Se}(12.9 \Omega)$ and $\mathrm{Au}(16.0 \Omega) \mathrm{CEs}$, which indicates the superior electrical conductivity of CuAgSe. Moreover, the CuAgSe CE has the smallest $R_{\mathrm{ct}}$ value (0.67 $\Omega$; compared with $\mathrm{Cu}_{2-x} \mathrm{Se}$ $(0.81 \Omega)$ and $\mathrm{Au}(42.43 \Omega) \mathrm{CEs})$, which means that the CuAgSe CE has the best electrocatalytic activity towards the reduction of polysulfide among the three CEs. This is consistent with the $J_{s c}$ values in the order of the CuAgSe $\left(17.57 \mathrm{mAcm}^{-2}\right)>\mathrm{Cu}_{2-x} \mathrm{Se}$ $\left(17.13 \mathrm{~mA} \mathrm{~cm}^{-2}\right)>\mathrm{Au} \quad\left(13.34 \mathrm{mAcm}^{-2}\right)$ CEs. The smallest $Z_{\mathrm{w}}$ value of the CuAgSe CE (4.17 $\Omega$ ) reveals efficient diffusion of 
the polysulfide electrolyte. The highest FF value for the QDSSCs with the CuAgSe CE can be attributed to the smallest $Z_{\mathrm{w}}$ and $R_{\mathrm{s}}$ values. Figure $6 \mathrm{~d}$ shows the logarithmic current density $(\log J)$ as a function of the voltage $(V)$ for the oxidation/reduction of polysulfide to form sulfide. The slopes for the anodic and cathodic branches are in the order of CuAgSe NTs $>\mathrm{Cu}_{2-x} \mathrm{Se}$ NTs $>\mathrm{Au}$. The larger slope for the CuAgSe NT indicates a larger exchange current density, which is consistent with the EIS results. Better electrochemical performance of the CuAgSe CE compared with that of the $\mathrm{Cu}_{2-x} \mathrm{Se} C E$ is due to the higher mobility of both $\mathrm{Cu}^{+}$and $\mathrm{Ag}^{+}$ions in the CuAgSe NTs. The electrical conductivity of a single NT, to provide direct evidence for comparison of the electrical performances of these two NTs, will be measured and reported in our next study. The higher conversion efficiency of QDSSCs from ternary and binary NT-based CEs is attributed to the higher stability of metal selenides in polysulfide electrolyte than that of the $\mathrm{Au}$ CE because good conductivity is retained by avoiding corrosion and passivation.

The superior electrical conductivity and electrocatalytic activity of CuAgSe NTs relative to $\mathrm{Cu}_{2-x} \mathrm{Se}$ NTs led to an enhancement in power conversion efficiency of QDSSCs made with CuAgSe CE $(\eta=5.61 \%)$ in comparison with that made with $\mathrm{Cu}_{2-x} \mathrm{Se} C \mathrm{CE}(\eta=5.19 \%)$, although this is not the highest record for QDSSCs. ${ }^{[43-46]}$ It should be noted that these values are lower than those in our previous reports because the photoelectrodes used herein are made from commercial $\mathrm{TiO}_{2}$ nanoparticles rather than porous $\mathrm{TiO}_{2}$ nanosheets, which could effectively scatter the incident light and improve the conversion efficiency. ${ }^{[47]}$ The use of commercial $\mathrm{TiO}_{2}$ nanoparticles would be important for evaluating the practical application of our 1D/2D CuAgSe NTs.

\section{Conclusion}

One-/two-dimensional pure ternary CuAgSe NTs were successfully prepared from $\mathrm{Cu}_{2-x}$ Se NTs by cation exchange with silver nitrate (or silver acetate) at room temperature within a short time. Fast cation exchange is due to the ionic characteristics of copper/silver chalcogenides, and the strong capability of copper and silver ions to diffuse into/out of the lattice. The CuAgSe NTs with a designed architecture were used to fabricate CEs for QDSSCs that showed better electrochemical performance and higher conversion efficiency $(\eta=5.61 \%)$ than those of the original $\mathrm{Cu}_{2-x}$ Se NT CE $(\eta=5.19 \%)$ and Au CE ( $\eta=$ $3.32 \%)$. Our research not only opens up a new way to design more effective CE catalysts for highly efficient QDSSCs, but also provides a facile method to fabricate nanostructures of ternary selenides with specifically designed architectures for diverse applications.

\section{Experimental Section}

\section{Chemicals}

$\mathrm{NaOH}\left(97.0 \%\right.$, Alfa Aesar), $\mathrm{Cu}\left(\mathrm{NO}_{3}\right)_{2} \cdot 3 \mathrm{H}_{2} \mathrm{O}(99.5 \%$, Aldrich), ethylenediamine $\left(99.0 \%\right.$, Alfa Aesar), hydrazine ( $35 \mathrm{wt} \%$ in $\mathrm{H}_{2} \mathrm{O}$, Aldrich), 2-mercaptoethanol (>99.0\%, Aldrich), selenium powder ( -325 mesh, $99.5 \%$, Alfa Aesar), silver nitrate (>99.0\%, Sigma-Aldrich), silver acetate ( $>99.99 \%$, Sigma-Aldrich), anhydrous ethanol (>99.5\%, Sigma-Aldrich), acetone (>99.9\%, Sigma-Aldrich), and Milli-Q water $(18.2 \mathrm{M} \Omega \cdot \mathrm{cm})$ were used as received.

\section{Synthesis of CuAgSe NTs}

$\mathrm{Cu}_{2-x}$ Se NTs were prepared as described elsewhere. ${ }^{[48]}$ In a typical synthesis, as-prepared $\mathrm{Cu}_{2-x} \mathrm{Se}$ NTs $(0.15 \mathrm{mmol})$ were dispersed in anhydrous ethanol $(0.5 \mathrm{~mL})$, followed by the addition of solutions $(2.5 \mathrm{~mL})$ of silver nitrate or silver acetate $(0.15 \mathrm{mmol})$ in ethanol under gentle stirring for 20-40 min. The black precipitates were purified by rinsing with distilled water and ethanol several times, followed by drying at room temperature.

\section{Evolution of CuAgSe NTs}

The evolution of NTs was investigated by characterizing samples collected at different reaction times. Two groups of experiments were performed. The first group of experiments were performed by using silver nitrate for the cation-exchange reaction, and the samples were collected at 1, 2, 10, and $20 \mathrm{~min}$. The second group of experiments were conducted by using silver acetate for cation exchange, and the samples were collected at 1, 2, 10, 20, and $60 \mathrm{~min}$.

\section{Characterization of nanostructures}

Powder XRD patterns for all samples were collected by using $\mathrm{Cu}_{\mathrm{ka1}}$ radiation $(\lambda=1.5406 \AA)$ at $40 \mathrm{kV}$ and $25 \mathrm{~mA}$ with a position-sensitive detector. EDX, XPS, and ICP-AES measurements were used to characterize the chemical composition and crystal structure of the samples. The FE-SEM images of all the samples were collected by using a JEOL JMS 7500-FA microscope with an accelerating voltage of $5 \mathrm{kV}$ and a secondary electron detector. The TEM images were collected on a JEOL ARM200F microscope operated at $200 \mathrm{kV}$.

\section{Preparation of photoelectrodes}

CdS- and CdSe-sensitized $\mathrm{TiO}_{2}$ working electrodes were prepared by successively casting the commercial $\mathrm{TiO}_{2}$ pastes on fluorinedoped tin oxide (FTO) substrates by using the doctor blade technique. The $\mathrm{TiO}_{2}$ film was composed of a $13.7 \mu \mathrm{m}$ transparent layer (18NR-T paste, Dyesol). The working electrodes were gradually heated at $100^{\circ} \mathrm{C}$ for $15 \mathrm{~min}$ and $500^{\circ} \mathrm{C}$ for $30 \mathrm{~min}$, respectively. ${ }^{[38]}$

\section{Preparation of CEs}

The CuAgSe and $\mathrm{Cu}_{2-x}$ Se electrodes were prepared on FTO substrates by the doctor blade technique with $\mathrm{CuAgSe}$ and $\mathrm{Cu}_{2-x} \mathrm{Se}$ pastes, respectively. The pastes were prepared from CuAgSe and $\mathrm{Cu}_{2-x}$ Se powders according to a previous study with some modifications. $^{[39]}$ The newly formed films were annealed at $350^{\circ} \mathrm{C}$ for $30 \mathrm{~min}$ in an argon atmosphere to remove the binder and enhance the contact between the film and substrate. For comparison, gold electrodes were prepared by sputtering to yield a thickness of approximately $50 \mathrm{~nm}$ (obtained from the calibration curve of the sputtering). 


\section{Assembly and measurements of QDSSCs}

The solar cells were fabricated by assembling the CE (CuAgSe, $\mathrm{Cu}_{2-x} \mathrm{Se}$, and $\mathrm{Au}$ ) and (QD-sensitized $\mathrm{TiO}_{2}$ film electrode with a binder clip separated by a $60 \mu \mathrm{m}$ thick spacer. A mask with a window area of $0.16 \mathrm{~cm}^{2}$ was clipped onto the $\mathrm{TiO}_{2}$ side to define the active area of the cell during testing. The polysulfide electrolyte was composed of $2 \mathrm{M} \mathrm{Na}_{2} \mathrm{~S}, 2 \mathrm{M} \mathrm{S}$, and $0.2 \mathrm{M} \mathrm{KCl}$ in Milli$\mathrm{Q}$ water. For QDSSCs assembled under each set of conditions, at least eight cells were prepared and tested in parallel, and the one with the medium value was chosen for the final data. For EIS and Tafel polarization measurements, symmetric dummy cells were assembled from two identical CEs with the same polysulfide electrolyte. The active area of the dummy cells was $0.64 \mathrm{~cm}^{2}$. The $J-V$ tests on the QDSSCs were performed under one sun conditions by using an air mass (AM) 1.5 solar simulator (Oriel), which was carefully calibrated with certified silicon solar cells. The light intensity of the solar simulator was adjusted to $100 \mathrm{~mW} \mathrm{~cm}^{-2}$ by using an optical power meter (Newport, 1918-c) with a detector (818P-04025). J-V curves were obtained by applying an external bias to the cell, and measurements were recorded by using a Keithley model 2420 digital source meter. The IPCE plotted as a function of the excitation wavelength was obtained by using a Newport 1918c power meter under irradiation of a $300 \mathrm{~W}$ Oriel xenon light source with an Oriel Cornerstone $2601 / 4 \mathrm{~m}$ monochromator in direct-current mode. The EIS results were collected with dummy cells by using a Solartron 1260 frequency-response analyzer in combination with a Solartron 1480 potentiostat in the dark. The applied bias voltage and alternating current (ac) amplitude were set at $0 \mathrm{~V}$ and $10 \mathrm{mV}$, and the frequency ranged from 106 to $0.1 \mathrm{~Hz}$. Then, the Tafel polarization measurements were performed at a scan rate of $20 \mathrm{mVs}^{-1}$ on an electrochemical workstation (CHI660d).

\section{Acknowledgements}

X.Q.C. gratefully acknowledges funding from the Chinese Scholarship Council (CSC) (201206770014). Z.L. acknowledges support from the Australian Research Council (ARC) through the Discovery Projects DP130102699 and DP130102274, the Natural National Science Foundation of China through a project 81471657, Jiangsu Specially Appointed Professorship, and a Project Funded by the Priority Academic Program Development of Jiangsu Higher Education Institutions (PAPD). S.X.D. is grateful for support from the ARC through the Linkage Project LP120200289. We also appreciate support from the Electron Microscopy Centre at UOW (Linkage Infrastructure, Equipment and Facility Grant LE120100104 for JEOL JEM-ARM200F), and thank Dr. Tania Silver for critical reading of the manuscript and Dr. Dongqi Shi for carrying out XPS measurements.

Keywords: copper - electrochemistry - ion exchange nanotubes $\cdot$ silver

[1] J. Xu, C. S. Lee, Y. B. Tang, X. Chen, Z. H. Chen, W. J. Zhang, S. T. Lee, W. X. Zhang, Z. H. Yang, ACS Nano 2010, 4, 1845-1850.

[2] W. T. Bi, M. Zhou, Z. Y. Ma, H. Y. Zhang, J. B. Yu, Y. Xie, Chem. Commun. 2012, 48, 9162-9164.

[3] B. Mukherjee, A. Peterson, V. Subramanian, Chem. Commun. 2012, 48, $2415-2417$.

[4] C. M. Lieber, Z. L. Wang, MRS Bull. 2007, 32, 99-108.
[5] G. Q. Zhang, B. Y. Xia, C. Xiao, L. Yu, X. Wang, Y. Xie, X. W. Lou, Angew. Chem. Int. Ed. 2013, 52, 8643-8647; Angew. Chem. 2013, 125, 88058809.

[6] C. X. Fang, S. Y. Zhang, P. F. Zuo, W. Wei, B. K. Jin, J. Y. Wu, Y. P. Tian, J. Cryst. Growth 2009, 311, 2345-2351.

[7] M. T. Neshkova, V. D. Nikolova, A. M. Bond, V. Petrov, Electrochim. Acta 2005, 50, 5606-5615.

[8] S. J. Peng, T. R. Zhang, L. L. Li, C. Shen, F. Y. Cheng, M. Srinivasan, Q. Y. Yan, S. Ramakrishna, J. Chen, Nano Energy 2015, 16, 163-172.

[9] J. W. Earley, Am. Mineral. 1950, 35, 345-347.

[10] A. J. Frueh, G. K. Czamanke, C. H. Knight, Z. Kristallogr. 1957, 108, 389 396.

[11] S. Ishiwata, Y. Shiomi, J. S. Lee, M. S. Bahramy, T. Suzuki, M. Uchida, R. Arita, Y. Taguchi, Y. Tokura, Nat. Mater. 2013, 12, 512-517.

[12] A. J. Hong, T. Li, H. X. Zhu, X. H. Zhou, Q. Y. He, W. S. Liu, Z. B. Yan, J. M. Liu, Z. F. Ren, Solid State Ionics 2014, 261, 21-25.

[13] R. B. Baikulov, Y. G. Asadov, Inorg. Mater. 2005, 41, 338-342.

[14] C. Han, Q. Sun, Z. X. Cheng, J. L. Wang, Z. Li, G. Q. Lu, S. X. Dou, J. Am. Chem. Soc. 2014, 136, 17626-17633.

[15] Y. H. Gao, Z. Zheng, Y. P. Tian, Y. D. Zhang, Y. G. Zhang, Eur. J. Inorg. Chem. 2011, 4198-4203.

[16] S. Gupta, S. V. Kershaw, A. L. Rogach, Adv. Mater. 2013, 25, 6923-6943.

[17] D. H. Ha, A. H. Caldwell, M. J. Ward, S. Honrao, K. Mathew, R. Hovden, M. A. Koker, D. A. Muller, H. G. Hennig, R. D. Robinson, Nano Lett. 2014, $14,7090-7099$.

[18] W. van der Stam, Q. A. Akkerman, X. X. Ke, M. A. Huis, S. Bals, C. M. Donega, Chem. Mater. 2015, 27, 283-291.

[19] L. De Trizio, H. B. Li, A. Casu, A. Genovese, A. Sathya, G. C. Messina, L. Manna, J. Am. Chem. Soc. 2014, 136, 16277-16284.

[20] D. H. Son, S. M. Hughes, Y. D. Yin, A. P. Alivisatos, Science 2004, 306, $1009-1012$.

[21] I. Kriegel, J. Rodriguez-Fernandez, A. Wisnet, H. Zhang, C. Waurisch, A. Eychmuller, A. Dubavik, A. O. Govorov, J. Feldmann, ACS Nano 2013, 7, 4367-4377.

[22] S. L. Xiong, H. C. Zeng, Angew. Chem. Int. Ed. 2012, 51, 949-952; Angew. Chem. 2012, 124, 973-976.

[23] X. J. Wu, X. Huang, J. Q. Liu, H. Li, J. Yang, B. Li, W. Huang, H. Zhang, Angew. Chem. Int. Ed. 2014, 53, 5083-5087; Angew. Chem. 2014, 126, $5183-5187$.

[24] R. D. Robinson, B. Sadtler, D. O. Demchenko, C. K. Erdonmez, L. W. Wang, A. P. Alivisatos, Science 2007, 317, 355-358.

[25] J. Y. Tang, Z. Y. Huo, S. Brittman, H. W. Gao, P. D. Yang, Nat. Nanotechnol. 2011, 6, 568-572.

[26] H. B. Li, R. Brescia, R. Krahne, G. Bertoni, M. J. P. Alcocer, C. D'Andrea, F. Scotognella, F. Tassone, M. Zanella, M. De Giorgi, L. Manna, ACS Nano 2012, 6, 1637-1647.

[27] H. B. Li, R. Brescia, M. Povia, M. Prato, G. Bertoni, L. Manna, I. Moreels, J. Am. Chem. Soc. 2013, 135, 12270-12278.

[28] D. D. Zhang, A. B. Wong, Y. Yu, S. Brittman, J. W. Sun, A. Fu, B. Beberwyck, A. P. Alivisatos, P. D. Yang, J. Am. Chem. Soc. 2014, 136, 1743017433.

[29] K. Miszta, R. Brescia, M. Prato, G. Bertoni, S. Marras, Y. Xie, S. Ghosh, M. R. Kim, L. Manna, J. Am. Chem. Soc. 2014, 136, $9061-9069$.

[30] S. C. Riha, D. C. Johnson, A. L. Prieto, J. Am. Chem. Soc. 2011, 133, $1383-$ 1390

[31] X. Q. Chen, Z. Li, J. P. Yang, Q. Sun, S. X. Dou, J. Colloid Interface Sci. $2015,442,140-146$.

[32] L. W. Mi, W. T. Wei, Z. Zheng, G. S. Zhu, H. W. Hou, W. H. Chen, X. X. Guan, Nanoscale 2014, 6, 1124-1133.

[33] X. Q. Chen, Z. Li, S. X. Dou, ACS Appl. Mater. Interfaces 2015, 7, 13295 13302.

[34] V. Lesnyak, R. Brescia, G. C. Messina, L. Manna, J. Am. Chem. Soc. 2015, 137, 9315-9323.

[35] F. Grønvold, S. Stolen, Y. Semenov, Thermochim. Acta 2003, 399, 213224.

[36] K. C. Mills, Thermodynamic Data for Inorganic Sulphides, Selenides and Tellurides, Butterworths, London, 1974.

[37] C. W. Liu, Z. L. Qiu, F. Li, W. L. Meng, W. J. Yue, F. P. Zhang, Q. Q. Qiao, M. T. Wang, Nano Energy 2015, 12, 686-697.

[38] Y. Bai, H. Yu, Z. Li, R. Amal, G. Q. Lu, L. Z. Wang, Adv. Mater. 2012, 24, $5850-5856$. 
[39] Y. Bai, C. Han, X. Q. Chen, H. Yu, X. Zong, Z. Li, L. Z. Wang, Nano Energy 2015, 13, 609-619.

[40] J. K. Lee, D. Y. Son, T. K. Ahn, H. W. Shin, I. Y. Kim, S. J. Hwang, M. J. Ko, S Sul, H. Han, N. G. Park, Sci. Rep. 2013, 3, 1-8.

[41] P. K. Santra, P. V. Kamat, J. Am. Chem. Soc. 2012, 134, 2508-2511.

[42] M. X. Wu, X. A. Lin, A. Hagfeldt, T. L. Ma, Angew. Chem. Int. Ed. 2011, 50, 3520-3524; Angew. Chem. 2011, 123, $3582-3586$.

[43] J. Wang, I. Mora-Sero, Z. X. Pan, K. Zhao, H. Zhang, Y. Y. Feng, G. Yang, X. H. Zhong, J. Bisquert, J. Am. Chem. Soc. 2013, 135, 15913-15922.

[44] Z. X. Pan, I. Mora-Sero, Q. Shen, H. Zhang, Y. Li, K. Zhao, J. Wang, X. H. Zhong, J. Bisquert, J. Am. Chem. Soc. 2014, 136, 9203-9210.

[45] S. Jiao, Q. Shen, I. Mora-Sero, J. Wang, Z. X. Pan, K. Zhao, Y. Kuga, X. H. Zhong, J. Bisquert, ACS Nano 2015, 9, 908-915.
[46] K. Zhao, Z. X. Pan, I. Mora-Sero, E. Canovas, H. Wang, Y. Song, X. Q. Gong, J. Wang, M. Bonn, J. Bisquert, X. H. Zhong, J. Am. Chem. Soc. 2015, 137, 5602-5609.

[47] T. G. Deepak, G. S. Anjusree, S. Thomas, T. A. Arun, S. V. Nair, A. S. Nair, RSC Adv. 2014, 4, 17615-17638.

[48] X. Q. Chen, Z. Li, Y. Bai, Q. Sun, L. Z. Wang, S. X. Dou, Chem. Eur. J. 2015 21, 1055-1063.

Manuscript received: October 8, 2015

Revised: November 23, 2015

Final Article published: $\mathbf{\square}$ uI, 0000 


\section{FULL PAPERS}

X. Q. Chen, Y. Bai, Z. Li, * L. Z. Wang, S. X. Dou

Ambient Synthesis of One-/TwoDimensional CuAgSe Ternary Nanotubes as Counter Electrodes of Quantum-Dot-Sensitized Solar Cells

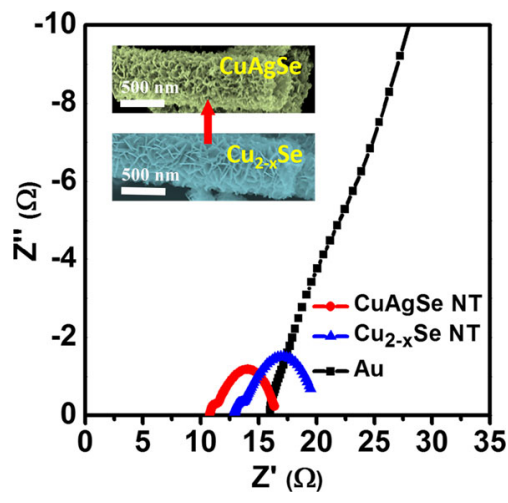

Metal exchange: One-/two-dimensional CuAgSe nanotubes are prepared from $\mathrm{Cu}_{2-x} \mathrm{Se}$ nanotubes by a cation-exchange approach and explored as counter electrodes in quantum-dot-sensitized solar cells to achieve high conversion efficiency (see figure). 